Tom Lelmezh is head of the Mental Health Act Office, both at South West London and St George's Mental Health NHS Trust.

doi: $10.1192 / p b .35 .3 .117 b$

\section{Proposed College working party on psychiatry and religion}

The establishing of a Royal College of Psychiatrists' working party to consider the boundaries of psychiatry and religion, as suggested by Poole \& Higgo, ${ }^{1}$ is indeed a pragmatic, constructive and, in our view, long overdue proposal.

It was in 1991 that our Patron, the Prince of Wales, first reminded the College that therapy involved body, mind and spirit. ${ }^{2}$ In that same year, the current President Dinesh Bhugra organised a meeting at the Institute of Psychiatry at which Bill Fulford cogently urged delegates to explore the limits of tolerance at the boundaries of psychiatric practice and religious belief. ${ }^{3}$

Can the President please, in his last year of office, establish a working party which would consider these matters, consult widely and make recommendations relevant to the core clinical, research and educational objectives of the College? Such a working party will require the arms-length approach of transcultural psychiatry as well as a broad, multifaith perspective and astute leadership, fully sensitive to the concerns of religious and secular psychiatrists as well as service users and other health professionals.

If the World Psychiatric Association can be approaching an international consensus on this subject, ${ }^{4}$ then surely the College can usefully now give a lead in Europe where these matters are particularly pressing.

\section{Declaration of interest}

J.C. is a Christian from the Methodist tradition. A.J.G. was recently ordained Deacon in the Church of England.

1 Poole R, Higgo R. Psychiatry, religion and spirituality: a way forward. Psychiatrist 2010; 34: 452-3.

$2 \mathrm{HRH}$ The Prince of Wales. Lecture by HRH The Prince of Wales, as Patron, to the Royal College of Psychiatrists, Brighton, Friday 5 July 1991. Br J Psychiatry 1991; 159: 763-8.

3 Fulford KWM. Religion and psychiatry: extending the limits of tolerance. In Psychiatry and Religion: Context, Consensus and Controversies (ed D Bhugra): 5-23. Routledge, 1996.

4 Verhagen P, van Praag HM, Lopez-lbor JJ, Cox JL, Moussaoui D (eds). Religion and Psychiatry: Beyond Boundaries. Wiley Blackwell, 2010.

John Cox is professor emeritus, Honorary Fellow and Past President, Royal College of Psychiatrists, and Co-Chair, Centre for Faith Science and Values in Healthcare, University of Gloucestershire, email: john1.cox@virgin.net. Alison J. Gray is liaison psychiatrist, Birmingham and Solihull Mental Health NHS Foundation Trust, WholeCare Research Fellow and Research Associate, University of Birmingham School of Psychology.

doi: $10.1192 / \mathrm{pb} .35 .3 .118$

\section{Not all 'crisis teams' are the same}

I am concerned by the claims made in the paper by Forbes et al. ${ }^{1}$ It purports to add to the literature relating to the introduction of a crisis resolution and home treatment team (CRHTT), by demonstrating little impact on bed use and increased compulsory admissions. This is misleading as the study actually shows the effect that a new CRHTT, which does not adhere to the consensus model, may have as part of a complex, changed system.

The paper describes admission and compulsory admission rates before and after a service redesign (which includes the inception of a CRHTT), but reports these as if the set up of the CRHTT was the only important change. In reality, the changes included a reduction in in-patient beds, reprovision of beds several miles away, and presumably uncertainty and anxiety in staff during the change period.

I am not surprised by the lack of impact on bed use and the increase in compulsory admissions. The CRHTT did not include key elements associated with reduced admissions as determined by evidence and the National Audit Office. ${ }^{2-4}$ First, the Midlothian team had no designated consultant or social worker (although there was 'ready access' to the latter). Second, the CRHTT did not do its own face-to-face gatekeeping in all cases, and the proportion of admissions subject to gatekeeping by the CRHTT is not supplied. Third, the team did not operate a 24-hour service.

It is vital to communicate accurately with commissioners and others about the economic value, safety and effectiveness of psychiatric services. Not all teams providing frequent visits outside of hospital are a CRHTT, but the distinction is not likely to be widely understood. The development of accreditation criteria for CRHTTs is now urgent.

1 Forbes NF, Cash HT, Lawrie SM. Intensive home treatment, admission rates and use of mental health legislation. Psychiatrist 2010; 34: 522-4.

2 Joy $C B$, Adams CE, Rice K. Crisis intervention for people with severe mental illnesses. Cochrane Dat Syst Rev 2006; 4: CD001087.

3 Glover G, Arts G, Babu KS. Crisis resolution/home treatment teams and psychiatric admission rates in England. Br J Psychiatry 2006; 189: 441-5.

4 National Audit Office. Helping People through Mental Health Crisis: The Role of Crisis Resolution and Home Treatment Services. TSO (The Stationery Office), 2007.

Nicky Goater is consultant psychiatrist, West London Mental Health NHS Trust, London, email: nicky.goater@wlmht.nhs.uk

doi: 10.1192/pb.35.3.118a

\section{Simulated patients - stimulated patients?}

Mitchison \& Khanna ${ }^{1}$ contribute an interesting letter to The Psychiatrist about the experience of role-playing actors, or simulated patients, who have become ubiquitous in OSCEbased examinations (such as the CASC) in medicine and psychiatry. Using qualitative methods, they briefly describe aspects of the simulated patients' experience, but focus on one: the emotional stress the actors can experience after roleplaying psychiatric patients repeatedly over the course of an examination.

The role of simulated patients in psychiatric OSCEs is a lightly researched topic. We conducted a study in 2009 looking at the role in examinations of the same population that Mitchison \& Khanna describe, i.e. UK MRCPsych trainees. ${ }^{2}$ One finding was that simulated patients and examiners scored 'empathy' and 'communication' differently (unlike the real examination, we asked the actors to mark the candidates). In a post-hoc unpublished exploration of why this might be (by using a questionnaire with both groups), we were unable to find the answer to this question. 